\title{
LIFESTYLE CHARACTERISTICS OF POOR AND RICH PEOPLE IN POLAND
}

\author{
ANNA SĄCZEWSKA-PIOTROWSKA \\ University of Economics in Katowice, Faculty of Economics, \\ Department of Labour Market Research and Forecasting, 1 Maja St. 50, Katowice, Poland \\ email: anna.saczewska-piotrowska@ue.katowice.pl \\ DAMIAN PIOTROWSKI \\ Medical University of Silesia, School of Medicine with the Division of Dentistry in Zabrze, \\ Department of Infectious Diseases and Hepatology, Aleja Legionów 49, Bytom, Poland \\ email: dpiotrowski@sum.edu.pl
}

\begin{abstract}
The health of individuals and communities depends on various factors. Medical condition is mostly related to unhealthy characteristics such as smoking, heavy alcohol consumption, obesity and lack of physical activity. These characteristics may occur singly or they can accumulate which can contribute to serious diseases at very young age. The lifestyle vary depending on socio-economic characteristics of people, e.g. age, sex, education, place of residence, income, kind of job. The aim of this paper was to compare lifestyle characteristics of poor and rich people. The attention was paid on certain unhealthy characteristics: alcohol consumption, smoking, overweight and obesity, and physical activity. There were compared shares of smoking, drinking too much alcohol, overweight and obese, and physically inactive among poor, middle class and rich people. The shares of leading a healthy lifestyle (no unhealthy characteristics) were also compared. The logistic regression models were estimated to determine the impact of economic situation to lifestyle behaviour (controlling for other variables: sex, age, education and place of residence). Using the odds-ratios there was evaluated the relationship between cigarette smoking and other unhealthy characteristics.
\end{abstract}

Key words: lifestyle, poverty, richness, health

JEL Codes: D31, I12, I14

DOI: 10.15611/amse.2017.20.32

\section{Introduction}

Income situation has an impact on many aspects of people's lives. Rich and poor people purchase other products, use other services and spend free time in another way. They have also different habits. These components are part of the lifestyle. Lifestyle has a very large impact on health condition. People leading unhealthy lifestyle live shorter and they get sick more often. Unhealthy society also generates higher costs for health care. The aim of the paper was to compare lifestyle characteristics of poor and rich people. It was hypothesized that rich people lead a healthier lifestyle. The rich people are generally better educated and thus more aware of the harmful effects of smoking or lack of physical activity. The attention in the paper was paid on certain unhealthy characteristics: heavy alcohol consumption, smoking, overweight and obesity, and lack of physical activity. There were compared shares of smoking, drinking too much alcohol, overweight and obese, and physically inactive among 
poor, middle class and rich people. The shares of leading a healthy lifestyle (no unhealthy characteristics) were also compared. The logistic regression models were estimated to determine the impact of economic situation to lifestyle behaviour (controlling for other variables: sex, age, education and place of residence). Using the odds-ratios (OR) there was evaluated the relationship between cigarette smoking and other unhealthy characteristics among poor, middle class and rich people, which allows to answer the question whether income situation change the odds of accumulation of unhealthy characteristics.

\section{Poverty, middle class and richness}

In the conducted study poor, middle class and rich people were defined as members of poor, middle class and rich households, respectively. It was assumed that the personal income is not so much influencing on lifestyle as household income. For example, high income individuals share their income with others members of households - all household members have access to this high income which have an influence on their lifestyle. Different situation, high disposable income divided for several household members may be too low to meet the basic needs of all members, including person who achieves high income.

The poor, the middle class and the rich can be defined in different ways. The poverty line is defined as the cutoff income point below which a household is considered to be poor, and analogously the richness line as the cutoff income point above which household is considered to be rich. The middle class may be defined as those living between poverty and richness thresholds. We will focus only on poverty and richness lines in relative terms as a percent of the median ${ }^{1}$.

One of the primary indicators used by Eurostat is the at-risk-of-poverty rate calculated using the $60 \%$ threshold ( $60 \%$ of the median income). However, it should be noted that atrisk-of-poverty rate is also calculated using the $40 \%$ threshold, the $50 \%$ threshold and the $70 \%$ threshold. This three rates are part of one of the secondary indicators - dispersion around the at-risk-of-poverty threshold (European Commission, 2010). The richness is often defined as $200 \%$ of the median, $300 \%$ of the median or $400 \%$ of the median. Some authors defined (based on the median) three categories: affluent (300\% of the median), rich (500\%) and superrich (1000\%). Relative thresholds of richness were used by Brzeziński (2010), Peichl et al. (2010), Sączewska-Piotrowska (2015), Franzini et al. (2016). In the analysis there were defined three states referring to the households (and simultaneously time to their members): poverty (equivalised income lower than $60 \%$ of the median), middle class (from $60 \%$ to $200 \%$ ), richness (higher than $200 \%$ ).

There was calculated equivalised income in order to take account of the differences in a household's size and its composition. There was used the modified OECD (Organisation for Economic Co-operation and Development) equivalence scale. This scale assigns 1 to the first adult of the household, 0.5 to each subsequent adult aged 14 or more and 0.3 to children (each person under 14).

\section{Unhealthy lifestyle and its consequences}

Health is a state of complete physical, mental and social well-being and not merely the absence of disease or infirmity (World Health Organization, 2017). There is a variety of factors that influence on health, including lifestyle. Four factors have been selected for this study: physical activity, overweight/obesity, smoking and excessive alcohol intake.

\footnotetext{
${ }^{1}$ Poverty and richness can be also considered in absolute terms. Absolute and relative poverty is widely discussed in the literature, e.g. Hagenaars and van Praag (1985), Panek (2011). Literature on richness is much poorer and mainly concerns relative richness, e.g. Franzini et al. (2016).
} 
Figure 1: Unhealthy lifestyle and some of its consequences

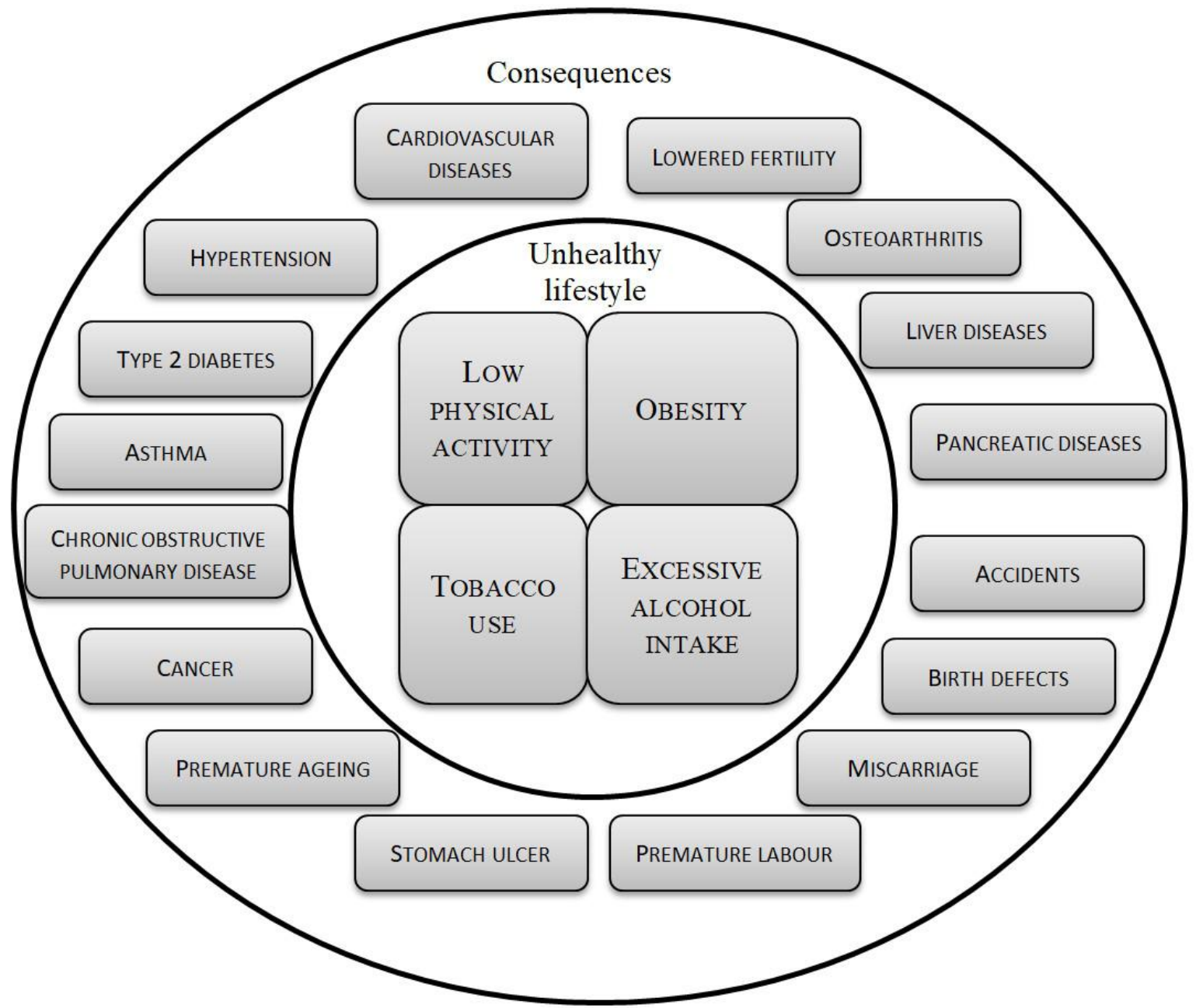

Source: The authors' work.

The concept that physical activity (PA) habits affect health and longevity dates back to the writings of ancient scholars, including Hippocrates and Galen. Observational studies from the 20th century conducted by Morris et al. $(1953,1966)$ showed the influence of occupational physical activity on the incidence of the coronary heart disease and longevity. Each time the comparison was made between group of sedentary workers (i.e. streetcar drivers or postal workers) and persons that need to move during their work (i.e. streetcar conductors in doubledecker vehicles), the results were similar: sedentary work was related to the greater coronary heart disease incidence. Current studies show the positive influence of physical activity not only on cardiovascular diseases incidence, but also on prevalence of type 2 diabetes, on quality of life, reduction of adverse effects of treatment, and on improving the prognosis in patients with diagnosed cancer. Large-scale epidemiological studies show that low exercise capacity is the highest risk factor for all-cause morbidity and mortality relative to other conditions including diabetes, hypertension, and obesity. The importance of physical activity has been pointed out in the construction of food and physical activity pyramid in 2016. The recommended "dose" of physical activity is at least half an hour of daily activity in any form.

Lack of physical activity may lead also to the overweight or to the obesity. According to the World Health Organization (WHO), overweight and obesity is abnormal or excessive fat accumulation that may impair health (World Health Organisation, 2016). Body mass index (BMI) is commonly used to diagnose overweight or obesity in adults. The definition of BMI 
is weight in kilograms divided by the square of height in meters. Overweight is diagnosed, if BMI is greater or equal 25 and obesity - if BMI is greater or equal 30 . The prevalence of obesity is rapidly increasing worldwide. In 2014, over 600 million adults were classified as obese (according to the BMI) and more than 1.9 billion adults were overweight (World Health Organization, 2016). In terms of diagnosis, numerous simple techniques have been developed except BMI: waist to hip ratio, waist circumference, bioelectrical impedance analysis, ultrasound and skinfold measurements. The obesity is related to higher incidence risk of: cardiovascular diseases (myocardial infarction, ischemic stroke), which were the leading cause of death in 2012, type 2 diabetes, but also higher prevalence of breast, colorectal and prostate cancer. Additionally, male obesity can negatively affect the male reproductive potential through among the others abnormal reproductive hormone and reduced semen quality (Kasum et al., 2016). The other consequences are musculoskeletal disorders, especially osteoarthritis as a highly disabling degenerative joints disease.

Use of tobacco products is a public health problem and the leading cause of deaths that depends on globally used psychoactive substance. Smoking of tobacco products is a risk factor for a number of serious health problems, it additionally increases the severity of complications of other health problems (e.g. high blood pressure, diabetes and asthma). Children exposed to second-hand tobacco smoke are at increased risk of respiratory infections, allergies and asthma. Smoking pregnant women are at higher risk of miscarriage, premature labour and having a low birth weight baby. Tobacco can be consumed by smoking (the most common intake), but it can be also chewed or sniffed. Finally, exposure to second-hand tobacco smoke also increases the risk of health problems among people who do not smoke themselves. The health risk associated with use of tobacco products include: cardiovascular diseases (coronary heart disease, ischemic stroke, atherosclerosis, including arterial occlusive diseases), chronic obstructive pulmonary disease, asthma, respiratory infections, cancers (of lung, but also of mouth, throat, larynx, esophagus, gall bladder, and breast), high blood pressure, diabetes, miscarriage, premature labour and low birth weight babies for pregnant women. The milder consequences of smoking are premature ageing and wrinkling of the skin, low fitness and longer recovery time after having a cold or flu (Humeniuk et al., 2010).

Alcohol intake is a risk factor for health problems and harmful consumption of alcohol is relevant cause of premature illness, disability and death. Heavy alcohol consumption leads to the health impairment, but also to the social problems including breakdown of relationships with family and friends or difficulty to maintain study or work. Low level alcohol consumption was shown to be associated (in studies undertaken in high-income countries) with some health benefits, mainly due to a reduction of risk for heart disease from middle age onwards. The lowest risk is associated with an average of $10 \mathrm{~g}$ of alcohol per day both for men and women. The dose of alcohol that is considered as safe is up to $20 \mathrm{~g}$ of pure alcohol per day for women, and up to 40-50 g of pure alcohol per day for men. Tolerance and dependence may develop as a result of regular drinking and dependent drinkers may suffer withdrawal symptoms if they reduce or stop their alcohol consumption. Severe alcohol withdrawal complicated by delirium tremens is a medical emergency. Withdrawal symptoms include tremor, sweating, anxiety, nausea, vomiting and diarrhoea, insomnia, headache, hypertension, hallucinations and convulsions. Women who consume alcohol during pregnancy are at risk of having babies with birth defects, learning and behavioural difficulties and impaired brain development. The negative influence of the unsafe alcohol consumption includes: liver diseases (inflammation, fibrosis, cirrhosis and cancer), pancreatic diseases (acute and chronic pancreatitis), inflammation and ulcers of esophagus and stomach, cancers of the mouth, throat and breast, elevation of blood pressure, ischemic stroke, muscle and nerve damage, permanent brain damage leading to memory loss, cognitive deficits, 
disorientation, anxiety, depression, difficulty remembering thing and solving problems. The acute influence covers hangovers, aggressive and violent behaviour, accidents and injury. Pregnant women that use alcohol are at risk of fetus brain damage and other birth defects (Babor and Higgins-Biddle, 2001).

The consequences of unhealthy lifestyle are dramatic for individual leading this kind of lifestyle, but they are also consequences for whole society. The more sick people in society, the higher the cost of health care. Therefore, healthy lifestyle is desirable from the point of view of individual (but first the individual must be aware of consequences of unhealthy lifestyle!) and from the point of view of whole society. In this situation, prevention plays a very important role, because it can improve length and quality of life and can also reduce health expenditure.

\section{Material and methods}

The study was conducted based on data from Social Diagnosis project (Council for Social Monitoring, 2015). This project is a panel study conducted in Poland. Each subsequent wave involves all available households from the previous wave and households from a new representative sample. Eight waves have been conducted from 2000 to 2015. Data from 2015 wave were used in the study. Sample was almost 19000 adults, who provided complete smoking, alcohol intake, PA and BMI data (sample sizes: smoking $n=18943$, alcohol consumption $n=18941$, PA $n=18739$, BMI $n=18847$ ). Smoking status was measured with the question: "do you smoke?". Alcohol intake was measured with the question: "in the last year, have you drunk too much alcohol?". Question "do you practice any sport or physical activity?" was used to measure physical activity. Overweight and obesity was measured based on BMI which was calculated using information about height and weight for each respondent. The respondents were classified as overweight and obese for BMI $\geq 25$.

Percentage (\%) and Pearson chi-square test for categorical variables were used to analyse unhealthy characteristics differences between poor, middle class and rich people.

For each unhealthy characteristic separate logistic regression models (unadjusted) were performed to evaluate the strength of associations for different potential factors with given characteristic as well as adjusted models to control for all potential confounders (sociodemographic variables). Both unadjusted and adjusted models were expressed as odds ratios (OR) with 95\% confidence interval (CI). Unadjusted and adjusted logistic regression models were also performed to evaluate the relationship between smoking and other lifestyle characteristics among poor, middle class and rich people. Dichotomised (sex and place of residence) and categorised (age and education) socio-demographic variables were included in all estimated models.

All statistical analyses were performed using R software (R Core Team, 2015).

\section{Results and discussion}

Table 1 and Figure 1 compare general characteristics between poor, middle class and rich people. There were significant relationships between each unhealthy characteristic and income situation $(P$ values at $<0.001)$. The poor were characterized by the highest percentages of smokers and physically inactive (31.3\% and $75.7 \%$, respectively). The better income situation, the lower the percentage of physically inactive. The middle class were characterized by the lowest percentage of alcohol drinkers (5.2\%). The percentages of drinking too much were very similar among poor and rich people $(7.4 \%$ and $7.3 \%$, respectively). The middle class were characterized by the highest percentage of overweight and obese $(60.1 \%)$. 
Table 1: Characteristics of the respondents, total and by income situation

\begin{tabular}{|c|c|c|c|c|c|}
\hline Variable & Poor & $\begin{array}{l}\text { Middle } \\
\text { class }\end{array}$ & Rich & Total & $P$ value* \\
\hline Cigarette smoking & & & & & $<0.001$ \\
\hline No & 1894 & 10983 & 1534 & 14411 & \\
\hline Yes & 864 & 3205 & 463 & 4532 & \\
\hline Drinking too much alcohol & & & & & $<0.001$ \\
\hline No & 2568 & 13481 & 1861 & 17910 & \\
\hline Yes & 191 & 705 & 135 & 1031 & \\
\hline Lack of physical activity & & & & & $<0.001$ \\
\hline No & 665 & 4766 & 936 & 6367 & \\
\hline Yes & 2068 & 9263 & 1041 & 12372 & \\
\hline Overweight and obesity & & & & & $<0.001$ \\
\hline No & 1272 & 5634 & 842 & 7748 & \\
\hline Yes & 1476 & 8487 & 1136 & 11099 & \\
\hline
\end{tabular}

*Statistical differences by income situation: Pearson chi-square test. $P$ value is considered significant at $<0.05$.

Source: The authors' work.

Figure 1: Unhealthy characteristics among poor, middle class and rich people (\%)
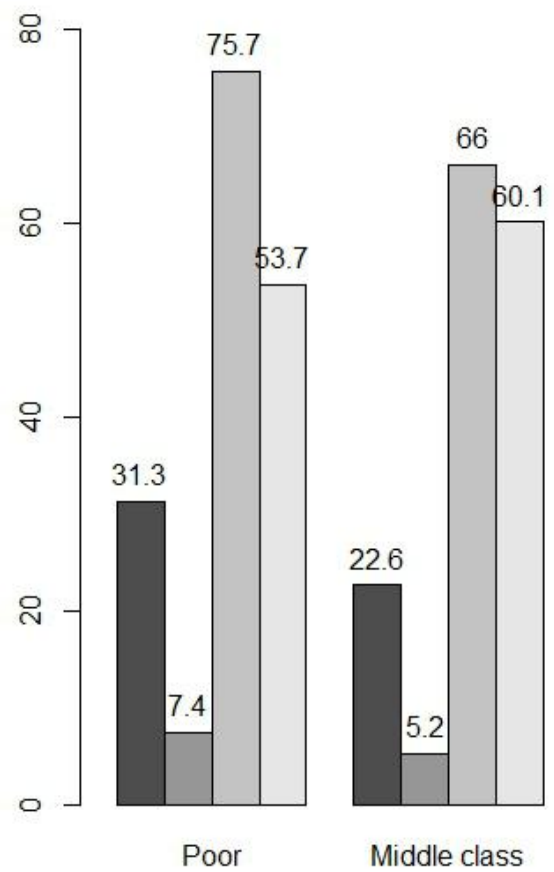

$\square$ Cigarette smoking $\square$ Drinking too much alcohol

$\square$ Lack of physical activity

$\square$ Overweight and obesity

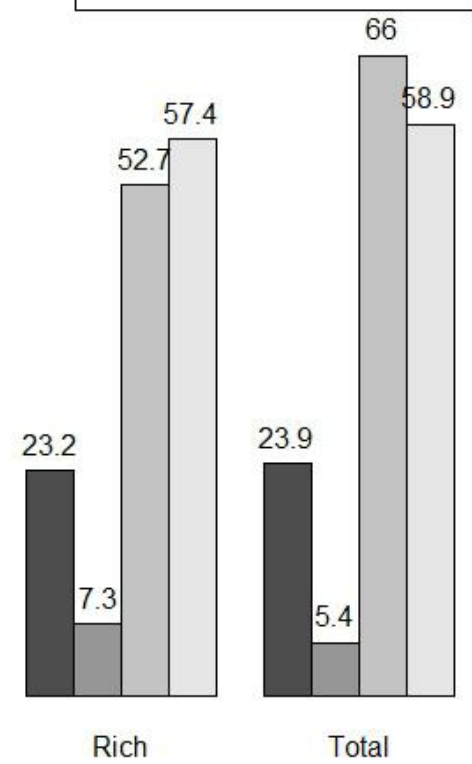

Source: The authors' work.

For each lifestyle behaviour (cigarette smoking, drinking too much alcohol, lack of physical activity, overweight and obesity) the reduced models (unadjusted) and full model (adjusted) including other covariates (sex, age, education, place of residence) were conducted. 
In almost all cases the likelihood ratio tests showed $(P$ values were considered significant at $<0.05)$ that models with regression parameters fit better than models including only intercepts. The exceptions were several models with one variable: rich (smoking and having BMI $\geq 25$ ), middle class (physical activity), and tertiary education (drinking too much alcohol).

Unadjusted logistic regression models showed that the odds of smoking for middle class were $75.4 \%$ of the odds for poor (Table 2). The odds for males were 2.184 times the odds for females. The odds were $93.7 \%$ higher for people with basic vocational education than for low educated people. The analysis also showed that the odds of smoking were lower for people with secondary education (the odds $11.6 \%$ lower) and for people with tertiary education (the odds 55.3\% lower). People living in urban areas had the higher odds than people living in rural areas (the odds 10.8\% higher). Logistic regression model adjusted for sex, age, education and place of residence gave the similar results to unadjusted models - the same direction of influence of variables. The main difference was very important from the point of view of conducted analysis - the odds of smoking for rich people were statistically lower than for poor people (in unadjusted model - statistically insignificant association).

Table 2: Logistic regression: unadjusted and adjusted associations between cigarette smoking and income situation

\begin{tabular}{|c|c|c|c|c|c|c|}
\hline \multirow{2}{*}{ Variable } & \multicolumn{3}{|c|}{ Unadjusted } & \multicolumn{3}{|c|}{ Adjusted* } \\
\hline & OR & $95 \%$ CI & $P$ value & OR & $95 \% \mathrm{CI}$ & $P$ value \\
\hline \multicolumn{7}{|l|}{ Income situation: } \\
\hline poor & ref. & & & ref. & & \\
\hline middle class & 0.754 & $0.670-0.812$ & $<0.001$ & 0.723 & $0.658-0.796$ & $<0.001$ \\
\hline rich & 0.955 & $0.856-1.066$ & 0.413 & 0.837 & $0.726-0.965$ & 0.015 \\
\hline \multicolumn{7}{|l|}{ Sex: } \\
\hline $\begin{array}{l}\text { male } \\
\text { female }\end{array}$ & $\begin{array}{l}2.184 \\
\text { ref. }\end{array}$ & $2.049-2.328$ & $<0.001$ & $\begin{array}{c}2.018 \\
\text { ref. }\end{array}$ & $1.881-2.165$ & $<0.001$ \\
\hline \multicolumn{7}{|l|}{ Age: } \\
\hline 34 and less & ref. & & & ref. & & \\
\hline $35-44$ & 1.255 & $1.154-1.364$ & $<0.001$ & 1.301 & $1.161-1.458$ & $<0.001$ \\
\hline $45-59$ & 1.720 & $1.608-1.840$ & $<0.001$ & 1.425 & $1.290-1.575$ & $<0.001$ \\
\hline 60 and more & 0.580 & $0.541-0.622$ & $<0.001$ & 0.653 & $0.589-0.725$ & $<0.001$ \\
\hline \multicolumn{7}{|l|}{ Education: } \\
\hline tertiary & 0.447 & $0.406-0.492$ & $<0.001$ & 0.371 & $0.323-0.426$ & $<0.001$ \\
\hline secondary & 0.884 & $0.827-0.946$ & $<0.001$ & 0.728 & $0.655-0.810$ & $<0.001$ \\
\hline $\begin{array}{l}\text { basic vocational } \\
\text { low }\end{array}$ & $\begin{array}{l}1.937 \\
\text { ref. }\end{array}$ & $1.812-2.071$ & $<0.001$ & $\begin{array}{c}1.173 \\
\text { ref. }\end{array}$ & $1.059-1.300$ & 0.002 \\
\hline $\begin{array}{l}\text { Place of residence: } \\
\text { urban areas } \\
\text { rural areas }\end{array}$ & $\begin{array}{l}1.108 \\
\text { ref. }\end{array}$ & $1.040-1.179$ & 0.001 & $\begin{array}{c}1.518 \\
\text { ref. }\end{array}$ & $1.411-1.635$ & $<0.001$ \\
\hline
\end{tabular}

$\mathrm{OR}=$ odds ratio, $\mathrm{CI}=$ confidence interval. *adjusted for sex, age, level of education and place of residence.

Source: The authors' work.

Based on unadjusted models statistically significant association between income situation and drinking too much alcohol was observed in the study (Table 3): the odds for the middle class were $29 \%$ lower than for the poor and the odds for the rich were higher (almost 30\%) than for the poor. The odds were definitely higher (4.73 times) for males than for females. The odds were $23.2 \%$ and $40.4 \%$ higher for people aged 35-44 and aged 45-59 (respectively) than for people aged 34 and less. The odds for basic vocational educated people were 1.36 times the odds for low educated people and the odds for secondary educated people were 0.866 the odds for low educated people. There was statistically significant association between drinking too much and place of residence - the odds for people from urban areas were $19.8 \%$ higher than for people from rural areas. Adjusted logistic regression models showed that the most of variables were statistically insignificant. The odds were still higher (4.536 times) for males 
than for females and higher (1.447 times) for people living in urban areas than for living in rural areas. Besides, the odds were lower for middle class people (than for poor people) and for people aged 60 and more (than people aged 34 and less).

Table 3: Logistic regression: unadjusted and adjusted associations between drinking too much alcohol and income situation

\begin{tabular}{|c|c|c|c|c|c|c|}
\hline \multirow{2}{*}{ Variable } & \multicolumn{3}{|c|}{ Unadjusted } & \multicolumn{3}{|c|}{ Adjusted* } \\
\hline & OR & $95 \% \mathrm{CI}$ & $P$ value & OR & $95 \%$ CI & $P$ value \\
\hline \multicolumn{7}{|l|}{ Income situation: } \\
\hline poor & ref. & & & ref. & & \\
\hline middle class & 0.710 & $0.620-0.814$ & $<0.001$ & 0.699 & $0.587-0.833$ & $<0.001$ \\
\hline rich & 1.299 & $1.078-1.567$ & 0.006 & 0.846 & $0.661-1.083$ & 0.184 \\
\hline \multicolumn{7}{|l|}{ Sex: } \\
\hline $\begin{array}{l}\text { male } \\
\text { female }\end{array}$ & $\begin{array}{c}4.732 \\
\text { ref. }\end{array}$ & $4.112-5.445$ & $<0.001$ & $\begin{array}{l}4.536 \\
\text { ref. }\end{array}$ & $3.902-5.273$ & $<0.001$ \\
\hline \multicolumn{7}{|l|}{ Age: } \\
\hline 34 and less & ref. & & & ref. & & \\
\hline $35-44$ & 1.232 & $1.057-1.436$ & 0.008 & 0.934 & $0.769-1.134$ & 0.491 \\
\hline $45-59$ & 1.404 & $1.239-1.591$ & $<0.001$ & 0.972 & $0.819-1.153$ & 0.743 \\
\hline 60 and more & 0.434 & $0.374-0.503$ & $<0.001$ & 0.455 & $0.375-0.550$ & $<0.001$ \\
\hline \multicolumn{7}{|l|}{ Education: } \\
\hline tertiary & 1.073 & $0.924-1.247$ & 0.353 & 1.000 & $0.788-1.268$ & 0.999 \\
\hline secondary & 0.833 & $0.732-0.948$ & $<0.006$ & 0.884 & $0.718-1.089$ & 0.247 \\
\hline $\begin{array}{l}\text { basic vocational } \\
\text { low }\end{array}$ & $\begin{array}{l}1.360 \\
\text { ref. }\end{array}$ & $1.200-1.541$ & $<0.001$ & $\begin{array}{l}1.025 \\
\text { ref. }\end{array}$ & $0.837-1.254$ & 0.813 \\
\hline \multicolumn{7}{|l|}{ Place of residence: } \\
\hline urban areas & $\begin{array}{c}1.198 \\
\text { ref }\end{array}$ & $1.064-1.350$ & 0.003 & $\begin{array}{l}1.447 \\
\text { ref }\end{array}$ & $1.263-1.659$ & $<0.001$ \\
\hline
\end{tabular}

$\mathrm{OR}=$ odds ratio, $\mathrm{CI}=$ confidence interval. *adjusted for sex, age, level of education and place of residence

Source: The authors' work.

Studying the factors of lack of physical activity (Table 4) unadjusted logistic regression models showed that almost all variables (besides middle class relative to poor) were statistically significant. The rich had lower odds of lack of physical activity than the poor (the odds $46.7 \%$ lower) The lack of physical activity was statistically associated with age - clearly higher odds (3 times) for people aged 60 and more, higher odds for people aged 45-59 (1.346 times) and lower odds for people aged 35-44 (30.7\% lower) than for people aged 34 and less. The odds of being physically inactive for the high educated were $30.9 \%$ of the odds for low educated. The odds for basic vocational people were 2.1 times the odds for low educated. Adjusted models gave the different results for several variables - the middle class had statistically lower odds of lack of physical activity (24.4\% lower) than the poor, people aged $35-44$ had higher odds (97.3\% higher) than people aged 34 and less, people with basic vocational education had lower odds $(12.3 \%$ lower) than low educated people.

Based on the unadjusted models it can be stated that the odds of overweight and obesity were $21.9 \%$ higher for middle class people than for poor people (Table 5). Sex and age changed the odds in a significant way - people aged 60 and more had higher (2.411 times) odds of overweight and obesity, and people with basic vocational education had higher odds (1.563 times) than low educated people. In adjusted model the odds for people aged 60 and more relative to aged 34 and less were definitely higher than in unadjusted models. Controlling for other variables the odds for the rich were 1.364 times the odds for the poor what is very important from the point of view of performed analysis. 
Table 4: Logistic regression: unadjusted and adjusted associations between lack of physical activity and income situation

\begin{tabular}{|c|c|c|c|c|c|c|}
\hline \multirow{2}{*}{ Variable } & \multicolumn{3}{|c|}{ Unadjusted } & \multicolumn{3}{|c|}{ Adjusted* } \\
\hline & OR & $95 \%$ CI & $P$ value & OR & $95 \% \mathrm{CI}$ & $P$ value \\
\hline \multicolumn{7}{|l|}{ Income situation: } \\
\hline poor & ref. & & & ref. & & \\
\hline middle class & 1.001 & $0.933-1.073$ & 0.981 & 0.756 & $0.683-0.838$ & $<0.001$ \\
\hline rich & 0.533 & $0.485-0.586$ & $<0.001$ & 0.610 & $0.531-0.701$ & $<0.001$ \\
\hline \multicolumn{7}{|l|}{ Sex: } \\
\hline $\begin{array}{l}\text { male } \\
\text { female }\end{array}$ & $\begin{array}{l}0.910 \\
\text { ref. }\end{array}$ & $0.860-0.964$ & 0.001 & $\begin{array}{l}0.847 \\
\text { ref. }\end{array}$ & $0.792-0.905$ & $<0.001$ \\
\hline \multicolumn{7}{|l|}{ Age: } \\
\hline 34 and less & ref. & & & ref. & & \\
\hline $35-44$ & 0.693 & $0.642-0.748$ & $<0.001$ & 1.972 & $1.783-2.182$ & $<0.001$ \\
\hline $45-59$ & 1.346 & $1.261-1.437$ & $<0.001$ & 2.850 & $2.601-3.123$ & $<0.001$ \\
\hline 60 and more & 3.000 & $2.808-3.206$ & $<0.001$ & 4.830 & $4.402-5.299$ & $<0.001$ \\
\hline \multicolumn{7}{|l|}{ Education: } \\
\hline tertiary & 0.309 & $0.288-0.332$ & $<0.001$ & 0.288 & $0.255-0.325$ & $<0.001$ \\
\hline secondary & 0.651 & $0.613-0.690$ & $<0.001$ & 0.475 & $0.427-0.528$ & $<0.001$ \\
\hline $\begin{array}{l}\text { basic vocational } \\
\text { low }\end{array}$ & $\begin{array}{l}2.100 \\
\text { ref. }\end{array}$ & $1.962-2.248$ & $<0.001$ & $\begin{array}{l}0.877 \\
\text { ref. }\end{array}$ & $0.783-0.981$ & 0.022 \\
\hline $\begin{array}{c}\text { Place of residence: } \\
\text { urban areas } \\
\text { rural areas }\end{array}$ & $\begin{array}{c}0.614 \\
\text { ref. }\end{array}$ & $0.580-0.650$ & $<0.001$ & $\begin{array}{c}0.732 \\
\text { ref. }\end{array}$ & $0.683-0.785$ & $<0.001$ \\
\hline
\end{tabular}

Source: The authors' work.

Table 5: Logistic regression: unadjusted and adjusted associations between overweight and obesity and income situation

\begin{tabular}{|c|c|c|c|c|c|c|}
\hline \multirow{2}{*}{ Variable } & \multicolumn{3}{|c|}{ Unadjusted } & \multicolumn{3}{|c|}{ Adjusted* } \\
\hline & OR & $95 \% \mathrm{CI}$ & $P$ value & OR & $95 \% \mathrm{CI}$ & $P$ value \\
\hline \multicolumn{7}{|l|}{ Income situation: } \\
\hline poor & ref. & & & ref. & & \\
\hline middle class & 1.219 & $1.141-1.303$ & $<0.001$ & 1.333 & $1.217-1.459$ & $<0.001$ \\
\hline rich & 0.935 & $0.851-1.028$ & 0.164 & 1.364 & $1.196-1.555$ & $<0.001$ \\
\hline \multicolumn{7}{|l|}{ Sex: } \\
\hline $\begin{array}{l}\text { male } \\
\text { female }\end{array}$ & $\begin{array}{l}1.799 \\
\text { ref. }\end{array}$ & $1.701-1.902$ & $<0.001$ & $\begin{array}{c}2.026 \\
\text { ref. }\end{array}$ & $1.899-2.162$ & $<0.001$ \\
\hline \multicolumn{7}{|l|}{ Age: } \\
\hline 34 and less & ref. & & & ref. & & \\
\hline $35-44$ & 0.784 & $0.728-0.844$ & $<0.001$ & 2.603 & $2.354-2.878$ & $<0.001$ \\
\hline $45-59$ & 1.562 & $1.467-1.664$ & $<0.001$ & 4.327 & $3.948-4.743$ & $<0.001$ \\
\hline 60 and more & 2.411 & $2.269-2.561$ & $<0.001$ & 5.908 & $5.394-6.471$ & $<0.001$ \\
\hline \multicolumn{7}{|l|}{ Education: } \\
\hline tertiary & 0.591 & $0.551-0.634$ & $<0.001$ & 0.910 & $0.813-1.018$ & 0.099 \\
\hline secondary & 0.846 & $0.798-0.896$ & $<0.001$ & 1.082 & $0.985-1.189$ & 0.100 \\
\hline $\begin{array}{l}\text { basic vocational } \\
\text { low }\end{array}$ & $\begin{array}{l}1.563 \\
\text { ref. }\end{array}$ & $1.469-1.663$ & $<0.001$ & $\begin{array}{c}1.175 \\
\text { ref. }\end{array}$ & $1.066-1.294$ & 0.001 \\
\hline $\begin{array}{c}\text { Place of residence: } \\
\text { urban areas } \\
\text { rural areas }\end{array}$ & $\begin{array}{l}0.882 \\
\text { ref. }\end{array}$ & $0.835-0.932$ & 0.001 & $\begin{array}{c}0.838 \\
\text { ref. }\end{array}$ & $0.784-0.895$ & $<0.001$ \\
\hline
\end{tabular}

$\mathrm{OR}=$ odds ratio, $\mathrm{CI}=$ confidence interval. *adjusted for sex, age, level of education and place of residence

Source: The authors' work.

The attention was also paid to co-prevalence of unhealthy characteristics (Table 6). There was a clear difference between poor, middle class and rich people due to shares of leading healthy lifestyle and shares accumulating unhealthy characteristics. Almost $18 \%$ of rich people and only $9.4 \%$ of poor people led a healthy lifestyle (no unhealthy factors). In the case 
of the rich (compared to the poor and the middle class) the higher percentages were cigarettes smokers and had BMI $\geq 25$. The rich were also more physically active. It can be emphasised that among the rich there were lower shares of people characterized by more than one unhealthy characteristic. The share of smokers and simultaneously physically inactive was definitely the lowest among the rich $(4.7 \%)$ as well as the share of physically inactive and having BMI $\geq 25$ (23.3\%). The share of smoking cigarettes, physically inactive, overweight and obese was also definitely the lowest among the rich $(7.2 \%)$. The exceptions were the shares of smoking and having BMI $\geq 25(4.3 \%)$, and drinking too much alcohol and having $\mathrm{BMI} \geq 25(1.2 \%)$.

Table 6: Co-prevalence of characteristics related to unhealthy lifestyle among poor, middle class and rich people (\%)

\begin{tabular}{ccccccccc}
\hline $\begin{array}{c}\text { Number } \\
\text { of } \\
\text { factors }\end{array}$ & $\begin{array}{c}\text { Cigarette } \\
\text { smoking }\end{array}$ & $\begin{array}{c}\text { Drinking } \\
\text { too } \\
\text { much } \\
\text { alcohol }\end{array}$ & $\begin{array}{c}\text { Lack of } \\
\text { physical } \\
\text { activity }\end{array}$ & $\begin{array}{c}\text { Overweight } \\
\text { and obesity }\end{array}$ & Poor & $\begin{array}{c}\text { Middle } \\
\text { class }\end{array}$ & Rich & Total \\
\hline 0 & - & - & - & - & 9.4 & 12.8 & 17.7 & 13.0 \\
1 & + & - & - & - & 2.9 & 2.8 & 3.8 & 2.9 \\
1 & - & + & - & - & 0.3 & 0.5 & 0.8 & 0.5 \\
1 & - & - & + & - & 19.0 & 16.2 & 13.2 & 16.3 \\
1 & - & - & - & + & 8.8 & 13.4 & 18.3 & 13.5 \\
2 & + & + & - & - & 0.5 & 0.4 & 0.6 & 0.5 \\
2 & + & - & + & - & 11.1 & 6.1 & 4.7 & 6.5 \\
2 & + & - & - & + & 1.9 & 2.9 & 4.3 & 2.9 \\
2 & - & + & + & - & 0.5 & 0.3 & 0.4 & 0.3 \\
2 & - & + & - & + & 0.3 & 0.7 & 1.2 & 0.7 \\
2 & - & - & + & + & 29.5 & 32.6 & 23.3 & 31.1 \\
3 & + & + & + & - & 2.5 & 0.8 & 0.7 & 1.0 \\
3 & + & + & - & + & 0.4 & 0.5 & 0.7 & 0.5 \\
3 & + & - & + & + & 10.4 & 8.2 & 7.2 & 8.4 \\
3 & - & + & + & + & 1.0 & 0.8 & 1.2 & 0.8 \\
4 & + & + & + & + & 1.7 & 0.9 & 1.2 & 1.1 \\
\hline
\end{tabular}

Source: The authors' work.

Table 7: Relationship between cigarette smoking and other unhealthy lifestyle characteristics among poor, middle class and rich people

\begin{tabular}{|c|c|c|c|c|c|c|}
\hline \multirow[b]{2}{*}{ Cigarette smoking } & \multicolumn{2}{|c|}{ Drinking too much alcohol } & \multicolumn{2}{|c|}{ Lack of physical activity } & \multicolumn{2}{|c|}{ Overweight and obesity } \\
\hline & $\begin{array}{l}\text { unadjusted OR } \\
(95 \% \mathrm{CI})\end{array}$ & $\begin{array}{l}\text { adjusted* OR } \\
(95 \% \mathrm{CI})\end{array}$ & $\begin{array}{l}\text { unadjusted OR } \\
\qquad(95 \% \mathrm{CI})\end{array}$ & $\begin{array}{l}\text { adjusted* OR } \\
(95 \% \mathrm{CI})\end{array}$ & $\begin{array}{l}\text { unadjusted OR } \\
(95 \% \mathrm{CI})\end{array}$ & $\begin{array}{l}\text { adjusted* OR } \\
(95 \% \mathrm{CI})\end{array}$ \\
\hline & & & 1.702 & 1.5 & & \\
\hline & 63 & $\left(2.99^{\prime}\right.$ & $(1.391$ & $(1.271$ & $(0.528$ & $(0.38$ \\
\hline middle class & 4.16 & 3.3 & 1.33 & 1.4 & 0.785 & \\
\hline & $(3.570-4.854)$ & $(2.872$ & $(1.224$ & $(1.281$ & $725-0.850)$ & $(0.582$ \\
\hline rich & $\begin{array}{c}3.192 \\
(2.236-4.555)\end{array}$ & $\begin{array}{c}2.948 \\
(2.023-4.298)\end{array}$ & $\begin{array}{c}1.419 \\
(1.148-1.754)\end{array}$ & $\begin{array}{c}1.304 \\
(1.031-1.651)\end{array}$ & $\begin{array}{c}1.023 \\
(0.828-1.264)\end{array}$ & $\begin{array}{c}0.815 \\
(0.640-1.037)\end{array}$ \\
\hline
\end{tabular}

*adjusted for sex, age, level of education and place of residence

Source: The authors' work.

The next step of analysis was to evaluate whether income situation change the odds of accumulation the unhealthy characteristics. There was evaluated the relationship between one 
unhealthy characteristic (there was selected cigarette smoking) and other characteristics (Table 7).

It is clear that there was a relationship between cigarette smoking and other unhealthy characteristics. On the one hand, cigarette smoking increased the odds of drinking too much alcohol and lack of physical activity. On the other hand, smoking decreased the odds of overweight and obesity. Unadjusted and adjusted models showed that the strongest relationship was between cigarette smoking and drinking too much alcohol. This relationship was the clearest for poor people (adjusted $\mathrm{OR}=4.269$ ) and the weakest for rich people (adjusted $\mathrm{OR}=2.948$ ). Cigarette smoking also increased the odds of lack of physical activity most for poor people (1.702 times) and decreased the odds of overweight and obesity for poor people (0.459 times).

The previous analyses of factors influencing on lifestyle gave the similar results to presented results of analysis. For example, the study conducted by Qi et al. (2006) showed that the richest group of people (income situation was evaluated on the basis of household income) was more likely to be regular physically active than the poorest group. This study also showed that the odds of regular smoking and alcohol consumption did not differ significant between the poorest and the richest groups. The study focused on rural areas in Hungary (Paulik et al., 2010) confirmed that material circumstance (categorised into poor, acceptable and good) has significant influence on healthy behaviour. They proved that the odds of healthy behaviour were higher for living in good material circumstances than for living in poor circumstances. The authors measured lifestyle by health-promoting behaviour index (HPB index) summing the total number of positive activities. Higher scores meant healthier lifestyle.

There are some studies referred to relationships between unhealthy characteristics. The previous analyses (e.g. Kaleta et al., 2009) showed that among men and women the odds of BMI $\geq 25$ were lower for tobacco smokers. Among women lack of physical activity was more likely for smokers; among men this relationship was statistically insignificant. According to authors' knowledge there are no studies concerning relationship between coprevalence of unhealthy factors and income situation. Therefore, no comparisons can be performed.

\section{Conclusion}

Based on conducted analysis it can be stated that income situation (categorised into poverty, middle class and richness) is a significant factor of unhealthy behaviour. However, there are other factors having more visible impact to lifestyle. It should be emphasised the importance of sex in smoking cigarettes and drinking too much alcohol. The age is also very important factor influencing on lack of physical activity and overweight and obesity.

Group of rich people - because of the achieved socio-economic position - is a benchmarking group. It can be expected that middle class and later the poorest part of society will copy the lifestyle of the richest part. This should mainly result in a increasing percentage of physically active people.

The relationship between prevalence of one unhealthy characteristic (cigarette smoking) and other characteristics was identified in the study. It should be noted that the strongest relationship between co-prevalence of unhealthy characteristics was identified for poor people and the weakest - for rich people.

Summarizing, on the one hand, rich people led the healthiest lifestyle - the highest percentage (compared to the poor and the middle class group) with no unhealthy characteristics, the lowest percentage of overweight and obese, the lower odds of prevalence of the other unhealthy characteristics among rich smokers. On the other hand, this healthy 
lifestyle of rich people does not differ so drastically from the lifestyle of middle class and poor people. There are only visible some positive aspects of lifestyle which should be imitated in the future by poorer groups of people.

The further research will be extended on studying lifestyle changes over the time and comparing persistence of lifestyle behaviour among poor, middle class and rich people. In the analysis there will be also included other factors related to lifestyle, e.g. sex, age, education.

\section{References}

[1] Babor, T.F., Higgins-Biddle, J.C. 2001. Brief Intervention For Hazardous and Harmful Drinking. A Manual for Use in Primary Care.

[2] Brzeziński, M. 2010. Income affluence in Poland. Social Indicators Research, vol. 99, pp. 285-299. DOI 10.1007/s11205-010-9580-0.

[3] European Commission 2010: Algorithms to compute Social Inclusion Indicators based on EU-SILC and adopted under the Open Method of Coordination. Doc. LC-ILC/39/09/ENrev.1, http://www.dst.dk/ext/747139308/0/.

[4] Franzini, M., Granaglia, E., Raitano, M. 2016. Extreme inequalities in contemporary capitalism. Should we be concerned about the rich?. Switzerland: Springer. ISBN: 978-3319-28810-9.

[5] Hagenaars, A.J.M., van Praag, B.M.S. 1985. A synthesis of poverty line definitions. Review of Income and Wealth, vol. 31, iss.2, pp. 139-154. DOI: 10.1111/j.14754991.1985.tb00504.x.

[6] Humeniuk, R., Henry-Edwards, S., Ali, R., Poznyak, V., V. Monteiro, M. 2010. The Alcohol, Smoking and Substance Involvement Screening Test (ASSIST). Manual for use in primary care. Geneva: WHO Press. ISBN 978-92-4-159938-2.

[7] Kaleta, D., Makowiec-Dąbrowska, T., Polańska, K., Dziankowska-Zaborszczyk, E., Drygas, W. 2009. Palenie tytoniu i inne negatywne zachowania zdrowotne wśród osób czynnych zawodowo. Medycyna Pracy, vol. 60, iss. 1, pp. 7-14.

[8] Kasum, M., Anić-Jurica, S., Čehić, E., Klepac-Pulanić, T., Juras, J., Žužul, K. 2016. Influenece of male obesity on fertility. Acta Clinica Croatica, vol. 55, No. 2, pp. 301-308. DOI: http://dx.doi.org/10.20471/acc.2016.55.02.18.

[9] Morris, J.N., Heady, J.A., Raffle, P.A., Roberts, C.G., Parks, J.W. 1953. Coronary heartdisease and physical activity of work. Lancet, vol. 262, No. 6796, pp. 1111-1120. DOI: http://dx.doi.org/10.1016/S0140-6736(53)91495-0.

[10] Morris, J.N., Kagan, A., Pattison, D.C., Gardner, M.J. 1966. Incidence and prediction of ischaemic heart-disease in London busmen. Lancet, vol. 288, No. 7463, pp. 553-559. DOI: http://dx.doi.org/10.1016/S0140-6736(66)93034-0.

[11]Panek, T. 2011. Ubóstwo, wykluczenie społeczne i nierówności. Teoria i praktyka pomiaru. Warszawa: SGH. ISBN 978-83-7378-624-0.

[12]Paulik, E., Bóka, F., Kertész, A., Balogh, S., Nagymajtényi, L. 2010. Determinants of health-promoting lifestyle behaviour in the rural areas of Hungary. Health Promotion International, vol. 25, no. 3, pp. 277-288, DOI: 10.1093/heapro/daq025.

[13]Peichl, A., Schaefer, T., Scheicher, C. 2010. Measuring richness and poverty: a micro data application to Europe and Germany. Review of Income and Wealth, vol. 56, iss. 3, pp. 597-619, DOI: 10.1111/j.1475-4991.2010.00404.x. 
[14]Qi, V., Phillips, S.P., Hopman, W.M. 2006. Determinants of a healthy lifestyle and use of preventive screening in Canada. BMC Public Health, vol. 6, 275, DOI: 10.1186/14712458-6-275.

[15]R Core Team 2015: R: a language and environment for statistical computing. Vienna: R Foundation for Statistical Computing, http://www.r-project.org/.

[16] Sączewska-Piotrowska, A., 2015, Identyfikacja determinant bogactwa dochodowego z zastosowaniem modelu logitowego. Zarządzanie i Finanse, vol. 13, no. 4/2, pp. 241-259.

[17] World Health Organization 2016: Obesity and overweight fact sheet, http://www.who.int/mediacentre/factsheets/fs311/en/.

[18]World Health Organization 2017: Constitution of WHO: principles, http://www.who.int/about/mission/en/. 
20th International Scientific Conference AMSE

Applications of Mathematics and Statistics in Economics 2017

Szklarska Poręba, Poland

30 August 2017 - 3 September 2017 